\title{
Interferon- $\gamma$-induced increases in intestinal epithelial macromolecular permeability requires the Src kinase Fyn
}

\author{
David Smyth, Van Phan, Arthur Wang and Derek M McKay
}

Interferon- $\gamma$ (IFN $\gamma)$ is an important immunoregulatory cytokine that can also decrease intestinal epithelial barrier function. Little is known about the intracellular signalling events immediately subsequent to IFN $\gamma /$ IFN $\gamma$ receptor interaction that mediate increases in epithelial permeability; data that could be used to ablate this effect of IFN $\gamma$ while leaving its immunostimulatory effects intact. This study assessed the potential involvement of Src family kinases in IFN $\gamma$-induced increases in epithelial permeability using confluent filter-grown monolayers of the human colon-derived T84 epithelial cell line. Inhibition of Src kinase with the pharmacologic PP1 and use of Fyn kinase-specific siRNA significantly reduced IFN $\gamma$-induced increases in epithelial permeability as gauged by translocation of noninvasive $E$. coli (HB101 strain) and flux of horseradish peroxidase (HRP) across monolayers of T84 cells. However, the drop in transepithelial resistance elicited by IFN $\gamma$ was not affected by either treatment. Immunoblotting revealed that IFN $\gamma$ activated the transcription factor STAT5 in T84 cells, and immunoprecipitation studies identified an IFN $\gamma$-inducible interaction between STAT5b and the PI3K regulatory subunit $\mathrm{p} 85 \alpha$ through formation of a complex requiring the adaptor molecule Gab2. siRNA targeting STAT5b and Gab2 reduced IFN $\gamma$-induced increases in epithelial permeability and phosphorylation of PI3K(p85 $\alpha$ ). PP1 and Fyn siRNA reduced IFN $\gamma$-induced PI3K activity (indicated by decreased phospho-Akt) and the formation of the STAT5b/PI3K(p85 $\alpha$ ) complex. Collectively, the results suggest the formation of a Fyn-dependent STAT5b/Gab2/PI3K complex that links IFN $\gamma$ to PI3K signalling and the regulation of macromolecular permeability in a model enteric epithelium.

Laboratory Investigation (2011) 91, 764-777; doi:10.1038/labinvest.2010.208; published online 14 February 2011

KEYWORDS: bacterial translocation; barrier function; PI3K

The intestinal epithelium is critical in the maintenance of health. It is responsible for nutrient and water absorption, it acts as an innate immune barrier to microbes entering the mucosa and it is increasingly appreciated as a regulator of mucosal immunity. ${ }^{1}$ Controlled and transient increases in epithelial permeability are homeostatic events, yet aberrant and prolonged loss of barrier function could mediate entry of excessive amounts of antigen and microbes into the mucosa to elicit inflammatory disease, as has been proposed for inflammatory bowel disease (IBD). ${ }^{2,3}$ Moreover, should bacteria move from the lumen of the gut into the bloodstream, the outcome can be sepsis and multiorgan failure.

Interferon- $\gamma(\operatorname{IFN} \gamma)$ is an immunoregulatory cytokine whose functions include increasing MHC I and II expression, activation of macrophages and regulation of $\mathrm{T}$ helper cell differentiation. Levels of IFN $\gamma$ are often elevated, locally and systemically, following microbial infection and in chronic inflammatory diseases including IBD. ${ }^{4}$ In addition to its pivotal role in immune regulation, numerous in vitro, and a lesser number of in vivo, studies reveal that IFN $\gamma$ decreases enteric epithelial barrier function. ${ }^{5-7}$ IFN $\gamma$-induced disruption of epithelial barrier function is accompanied by reduced expression of the tight junction (TJ) proteins, zonula occludens (ZO)-1 and occludin, ${ }^{6,7}$ and this would allow increased permeation of material between adjacent cells via the paracellular pathway. ${ }^{8}$ We, and others, have shown that IFN $\gamma$ can promote the transcytosis of bacteria across epithelial monolayers. ${ }^{9,10}$ Consequently, the elucidation of IFN $\gamma$ mediated intracellular signalling pathways can be pursued with the ambition of identifying epithelial target molecules, the inhibition of which would ablate IFN $\gamma$-induced increases in gut permeability while not interfering with its ability to activate immune cells to eliminate bacteria that gain access to the mucosa.

Gastrointestinal Research Group, Department of Physiology and Pharmacology, Calvin, Phoebe and Joan Snyder Institute of Infection, Immunity and Inflammation, University of Calgary, Calgary, Alberta, Canada

Correspondence: Dr DM McKay, PhD, Gastrointestinal Research Group, HSc 1717, Department of Physiology and Pharmacology, University of Calgary, 3330 Hospital Drive, Calgary, Alberta, T2N 4N1, Canada.

E-mail: dmckay@ucalgary.ca

Received 16 July 2010; revised 19 October 2010; accepted 21 October 2010 
Canonical IFN $\gamma$ signalling involves the phosphorylation, dimerization and nuclear translocation of signal transducer and activator of transcription (STAT)-1. ${ }^{11}$ Pharmacological inhibition of STAT1 tyrosine phosphorylation (ie, activation) failed to ameliorate IFN $\gamma$-induced reduction in transepithelial electrical resistance (TER, a marker of paracellular permeability), and subsequently a requirement for activation of PI3K during IFN $\gamma$-induced increases in epithelial permeability across monolayers of human colon-derived epithelial cell lines was shown. ${ }^{10,12}$ However, there is no indication that PI3K can bind the IFN $\gamma$ receptor, ${ }^{13}$ and hence intermediate structural or kinase molecules are needed to convert IFN $\gamma / \mathrm{IFN} \gamma$ receptor (IFN $\gamma \mathrm{R}$ ) interaction into $\mathrm{PI} 3 \mathrm{~K}$ activation.

Src kinases are a family of nonreceptor-associated tyrosine kinases that regulate several cell processes including cell growth and migration. ${ }^{14}$ Src has been implicated in STAT5 activation in response to hematopoietic growth factors and malignancy, ${ }^{15}$ and may lie upstream of PI3K activation, serving as a component of growth factor signalling. ${ }^{16,17}$ Activation of STAT5 in T-cell lines by IFN $\gamma$ has been shown but similar findings in epithelia have not been reported, whereas Src activity has been implicated in IFN $\gamma$ regulation of $\mathrm{Cl}^{-}$ secretion in the T84 epithelial cell line. ${ }^{18-20}$ Thus, we hypothesized that a Src kinase and/or STAT5 were intermediate molecules between the IFN $\gamma \mathrm{R}$ and PI3K in the regulation of epithelial barrier function.

The findings presented in this study suggest a novel signalling pathway whereby IFN $\gamma$ stimulates the activity of the Src kinase Fyn, leading to the formation of a complex containing STAT5b, Gab2 and the p $85 \alpha$ regulatory subunit of $\mathrm{PI} 3 \mathrm{~K}$. The complex assembly results in PI3K activation and a consequent increase in the macromolecular permeability characteristics of monolayers of the human colon-derived T84 epithelial cell line.

\section{MATERIALS AND METHODS Reagents}

Reagents, including cell culture supplements and pharmacological inhibitors, were purchased from Sigma-Aldrich (Oakville, ON, Canada) unless otherwise indicated. Src inhibitor PP1 was purchased from Biomol (Enzo Life Sciences, Plymouth Meeting, PA, USA) and LY294002 and AG490 were purchased from Calbiochem (EMD Chemicals, Gibbstown, NJ, USA). Recombinant human IFN $\gamma$ was purchased from Ebioscience (San Diego, CA, USA). Rabbit anti-STAT5a/b, anti-phosphotyrosine (694/699) STAT5a/b, anti-Akt, anti-phosphoserine (473) Akt, anti-STAT1a/b, antiphosphotyrosine (701) STAT1, anti-phosphotyrosine (452) Gab2, anti-phosphotyrosine (416) Src family and mouse anti-c-Src antibodies were purchased from Cell Signaling Technologies (NEB, Oakville, ON, Canada). Mouse antiSTAT5b was from Invitrogen (Burlington, ON, Canada) and mouse anti-Fyn kinase, rabbit anti-interferon response factor-1 (IRF-1) and goat anti-actin antibodies were purchased from Santa Cruz Biotech (Santa Cruz, CA, USA), Mouse anti-PI3K p85 $\alpha$, rabbit anti-Gab2 and mouse antiphosphotyrosine (4G10) were purchased from Millipore (Billerica, MA, USA). Mouse anti-IFN $\gamma \mathrm{R} 2$ was purchased from Abcam (Cambridge, MA, USA). Control mouse IgG and horseradish peroxidase (HRP)-conjugated secondary antibodies were purchased from Santa Cruz. Phosphoinositide 3,4,5, triphosphate $\left(\mathrm{PIP}_{3}\right)$ Mass ELISA kits were purchased from Echelon Biosciences (Salt Lake City, UT, USA). Nonpathogenic, noninvasive E. coli strain HB101 was a kind gift from Dr PM Sherman (Hospital for Sick Children, University of Toronto, Toronto, ON, Canada).

\section{Cell Culture}

The immortalized human colon-derived T84 epithelial cell line (ATCC, Manassas, VA, USA) was cultured at $37^{\circ} \mathrm{C} / 5 \%$ $\mathrm{CO}_{2}$ in 1:1 Dulbecco's modified Eagle's medium/Ham's F-12 medium supplemented with $2 \%(\mathrm{v} / \mathrm{v})$ penicillin-streptomycin, $1.5 \%$ HEPES, $5 \% \mathrm{NaHC}_{3}$, $1 \%$ L-glutamine, $1 \%$ sodium pyruvate (all from Invitrogen) and 10\% fetal bovine serum (PAA Laboratories, VWR International, Edmonton, $A B$, Canada). For assay of epithelial barrier function, $1 \times 10^{6}$ cells ( $1 \mathrm{ml}$ volume) were seeded onto $12 \mathrm{~mm}^{2}$ semi-permeable filter supports $(3.0 \mu \mathrm{m}$ pore size; Greiner Biosciences (VWR)) and cultured until electrically confluent (see below). For immunoprecipitation (IP) and immunoblotting experiments, $1 \times 10^{6} \mathrm{~T} 84$ cells/well were seeded in 12-well culture dishes and cultured until confluent as assessed by phasecontrast microscopy. For $\mathrm{PIP}_{3}$ synthesis assays, $5 \times 10^{6}$ cells were seeded onto $150 \mathrm{~mm}$ culture dishes and grown to confluence. In other experiments, cells of the human colonderived Caco 2 cell line were cultured and treated in a manner identical to that used for T84 cells.

In some signalling experiments, THP-1 cells (human monocytic cell line; ATCC) were differentiated by treatment with $20 \mathrm{nM}$ phorbol-12-myristyl-13-acetate (PMA) for $48 \mathrm{~h}$, and cells developed a stellate morphology typical of macrophages (see Figure3b, inset). Cells were subsequently stimulated with $10 \mathrm{ng} / \mathrm{ml} \mathrm{IFN} \gamma$ over the indicated times.

\section{Transient Transfection of T84 Cells with Small Interfering RNA (siRNA)}

siRNAs targeting STAT1, STAT5b, Gab2, Fyn and c-Src (and appropriate scrambled oligomer controls) were created using the Stealth siRNA oligomer design platform (Invitrogen); target oligomer sequences used in this study are shown in Table 1. A total of $20 \mathrm{pmol}$ of specific or scrambled control siRNA in Lipofectamine 2000/Opti-MEM $(500 \mu \mathrm{g} / \mathrm{ml}$; Invitrogen) was added to suspension cultures of T84 cells $\left(1 \times 10^{6} / \mathrm{ml}\right)$ in antibiotic-free FBS-containing culture medium. The cells were then either seeded onto filter supports for permeability experiments or 12-well culture dishes for signalling experiments. Following an overnight incubation, adherent cells were washed and transferred to antibioticcontaining culture medium until reaching confluence and assays were conducted as described below. 
Table 1 Sequences of the siRNA oligomers used in this study

\begin{tabular}{|c|c|c|c|}
\hline Target & Accession no. & Start site & Sequence \\
\hline Fyn & NM_002037 & $5^{\prime}-1057$ & $5^{\prime}$-GAGCGACAGCTATTGTCCTITGGAA-3' \\
\hline \multirow[t]{2}{*}{ Gab2 } & NM_012296 & $5^{\prime}-248$ & 5'-CAGGTAGATGCAGGCCTGACCTTA-3' \\
\hline & & control & 5'-CAGTAGAGACGTCCGCCAGTTGTTA-3' \\
\hline STAT5b & & control & $5^{\prime}$-CATAGTCACTGGATATCGTAGGTAA-3' \\
\hline \multirow[t]{2}{*}{ STAT1 } & NM_007315 & $5^{\prime}-1695$ & 5'-AAACCAGGCTGGCACAATTGGGTाT-3' \\
\hline & & control & 5'-AAATAACGTGTGACCGTCCGCCTI-3' \\
\hline \multirow[t]{2}{*}{ c-Src } & NM_005417 & $5^{\prime}-777$ & $5^{\prime}$-CGGCTCCAGATTGTCAACAACACAG-3' \\
\hline & & control & $5^{\prime}$-CGGACCTAGTGTAACAACACCTCAG-3' \\
\hline
\end{tabular}

Sequence selection and accession numbers for gene products selected for siRNA targeting. Shown are the sequences used for targeting of the indicated gene products; multiple siRNAs were designed for each protein target but sequences shown were used for the presented studies. Control oligomeric sequences are listed below each target. RNA oligomers were designed and synthesized using Stealth RNAi (Invitrogen).

\section{Epithelial Barrier Function}

For assessment of epithelial barrier function, filter-grown T84 or Caco 2 cell monolayers were treated with IFN $\gamma$ $(10 \mathrm{ng} / \mathrm{ml}) \pm$ pharmacological inhibitors (unless using siRNA transfected cells) added to the basal chamber of the culture well. Treatments were conducted in triplicate.

\section{Transepithelial electrical resistance}

TER across filter-grown T84 cells was assessed using a voltmeter and companion electrodes (Millipore). Monolayers in this study were considered electrically confluent when TER values were $\geq 1000 \mathrm{Ohms} \cdot \mathrm{cm}^{2}$, which typically occurred after 4-7 days of culture. ${ }^{21}$ Individual monolayer TER was measured at the start of each experiment (baseline value) and 24 and $48 \mathrm{~h}$ thereafter.

\section{HRP fluxes}

Immediately after the addition of IFN $\gamma \pm$ pharmacological inhibitors (times and doses denoted on figures) to T84 cell monolayers, HRP (20 ng type VI) was added to the apical chamber ( $1 \mathrm{ml}$ vol.) of the well, and $48 \mathrm{~h}$ later, three $10 \mu \mathrm{l}$ samples of culture medium were collected from the basolateral chamber, diluted $(1: 10)$ in $0.5 \% \mathrm{HTAB}$ buffer and HRP activity determined by spectrophotometric measurement $\left(\mathrm{OD}_{450} \mathrm{~nm}\right)$ of 3,3',5,5'-tetramethylbenzidine (TMB) oxidation after the reaction was terminated with $2 \mathrm{~N} \mathrm{H}_{2} \mathrm{SO}_{4}$. The amount of HRP was quantified against a standard concentration curve.

\section{Bacterial translocation}

Confluent T84 cell monolayers were transferred to antibioticfree culture medium, noninvasive E. coli (strain HB101, $10^{5}$ CFU) were added to the apical surface of the epithelium, and IFN $\gamma$ simultaneously added to the basolateral chamber ( \pm inhibitors as indicated). After $24 \mathrm{~h}, 100 \mu \mathrm{l}$ aliquots of basolateral media were collected, serial log dilutions made in
PBS and plated on antibiotic-free LB-Agar plates. Cultures were incubated overnight at $37^{\circ} \mathrm{C} / 5 \% \mathrm{CO}_{2}$ and resultant bacterial colonies were counted. Pharmacological inhibitors were tested for bacteriocidal or bacteriostatic activity by conducting E. coli growth assays in the presence or absence of experimental concentrations of the Src inhibitor, PP1 or the PI3K inhibitor, LY294002.

\section{IP and Immunoblotting}

Whole cell lysates were prepared by washing with ice-cold PBS, followed by scraping cells into ice-cold Triton X-100 buffer (25 mM Tris-HCl (pH 8), 125 mM NaCl, 5 mM EDTA, $1 \%(\mathrm{v} / \mathrm{v})$ Triton X-100) supplemented with protease and phosphatase inhibitors (Complete $\mathbb{R}$ ) protease inhibitor cocktail (Roche/Mannheim), $1 \mathrm{mM}$ sodium orthovanadate, $1 \mathrm{mM}$ sodium fluoride). Lysates were incubated with gentle agitation at $4{ }^{\circ} \mathrm{C}$ for $30 \mathrm{~min}$, centrifuged at $10000 \mathrm{~g}$ and supernatants were collected and stored at $-80{ }^{\circ} \mathrm{C}$. Protein concentrations were determined by Bradford assay (Bio-Rad, Hercules, CA, USA). Crude membrane extracts were prepared by lysing cells in Triton X-100 buffer as above, followed by dissolution of the pelleted fraction in $1 \%$ SDS/PBS at $65^{\circ} \mathrm{C}$ for $15 \mathrm{~min}$ followed by centrifugation.

For immunoblotting, $20 \mu \mathrm{g}$ of lysates was added to Laemmli buffer, boiled and resolved on $8 \%$ SDS-PAGE. With $1 \%$ SDS/PBS (membrane) lysates estimated equivalent quantities (adjusted to Triton X-100 protein lysate concentrations) were used. Separated proteins were blotted to Immobilon nitrocellulose membranes (Millipore), and blots were blocked at room temperature for $1 \mathrm{~h}$ in $5 \%$ nonfat milk/ wash buffer (0.1\% Tween-20/Tris-buffered saline (TBS/T)). Primary antibodies (for proteins as indicated in Results) were incubated in $1 \%$ bovine serum albumin/TBS/T (for phosphoprotein analysis) or 5\% non-fat milk/TBS/T (total proteins) overnight at $4{ }^{\circ} \mathrm{C}$ with gentle rocking. Blots were 
washed three times in TBS/T and species-appropriate, HRPconjugated secondary antibodies were applied with gentle rocking for $1 \mathrm{~h}$ at room temperature. Blots were washed, subjected to chemiluminescence (Western Lightning $\AA$ PLUS, PerkinElmer, Waltham, MA, USA) and subsequently exposed to Kodak XB-1 film (Eastman Kodak, Rochester, NY, USA).

For IP, $300 \mu \mathrm{g}$ of protein from total cell lysates was incubated with gentle rocking overnight at $4{ }^{\circ} \mathrm{C}$ with $2 \mu \mathrm{g} / \mathrm{ml}$ of indicated monoclonal antibody for a specific signalling or structural protein or an irrelevant $\operatorname{IgG}$ as a control for the IP process. Subsequently, immune complexes were adsorbed with EZ-view protein A-agarose beads (Sigma; $30 \mu \mathrm{l}$ per sample) by $1.5 \mathrm{~h}$ of gentle rocking at $4{ }^{\circ} \mathrm{C}$. Complexes were repeatedly washed with lysis buffer and once with PBS or TBS, and proteins were eluted in Laemmli buffer, boiled and resolved on SDS-PAGE for immunoblotting.

Where indicated, densitometric analyses were conducted on blots using Image J open-access software (NIH, Bethesda, MD, USA).

\section{PIP $_{3}$ and IP-10 ELISA}

T84 cells $\left(5 \times 10^{6}\right)$ were seeded onto $15 \mathrm{~cm}$ culture dishes and cultured to $\sim 80 \%$ confluence and subsequently treated with IFN $\gamma(20 \mathrm{ng} / \mathrm{ml})$ for the indicated times or with human epidermal growth factor (EGF; $20 \mathrm{ng} / \mathrm{ml}$ for $30 \mathrm{~min}$; a positive control for PI3K activation). Extraction of phosphoinositide lipids and a competitive ELISA for measurement of $\mathrm{PIP}_{3}$ was carried out as specified by the manufacturer's protocols.

Plastic-grown T84 epithelial cell monolayers were treated with IFN $\gamma \pm$ LY294002 (pan-PI3K inhibitor), and the amount of IP-10 liberated into the culture medium $24 \mathrm{~h}$ (or $48 \mathrm{~h}$ ) later was determined using Luminex technology.

\section{Statistical analysis}

Graphical data are presented as mean \pm s.d., with $n$ denoting the number of T84 cell preparations from a defined number of experiments. Where appropriate, data were assessed using Student's $t$-test or one-way analysis of variance (ANOVA) followed by post hoc pair-wise statistical comparisons with Tukey's or Dunnett's test. A statistical significance was deemed achieved if $P<0.05$.

\section{RESULTS}

\section{Pharmacological Inhibition of Src Kinases Reduces} IFN $\boldsymbol{\gamma}$-Induced Increases in Epithelial Permeability

A role for Src kinase in IFN $\gamma$ regulation of $\mathrm{Cl}^{-}$secretion by T84 cells has been shown; ${ }^{18}$ therefore, it was of interest to determine if IFN $\gamma$-mediated increases in epithelial permeability were influenced by Src kinase activity. As shown in Figure la and b, the increased passage of HRP and E. coli (strain HB101) across IFN $\gamma$-treated $(10 \mathrm{ng} / \mathrm{ml})$ T84 cell monolayers was abolished by co-treatment with the Src kinase inhibitor PP1 $(125 \mathrm{nM})$ and the PI3K inhibitor, LY294002 $(20 \mu \mathrm{M})$ (neither drug had bacteriostatic properties). Using transepithelial flux of HRP as a marker of epithelial barrier function, dose- and time-response studies revealed that $30 \mathrm{nM}$ PP1 blocked the IFN $\gamma$-induced increased transepithelial flux of HRP and the drug was equally effective if added $30 \mathrm{~min}$ before or $90 \mathrm{~min}$ after IFN $\gamma$ exposure (Figure 1c and d). IFN $\gamma$-induced increased HRP transcytosis across monolayers of $\mathrm{Caco} 2$ cells was also significantly reduced by PP1 (Figure 1c and d). In contrast, the drop in TER elicited by IFN $\gamma$ was not affected by $\mathrm{Src}$ kinase inhibition (Figure 1e), whereas consistent with earlier studies, ${ }^{10,12}$ inhibition of PI3K activity did reduce, in part, the drop in TER.

To examine Src activation, we assessed IFN $\gamma$-stimulated Src phosphorylation at the Y416 residue (an auto-phosphorylation site) $2 \mathrm{~h}$ post-cytokine application (Figure 1f). Phosphorylation of two immunoreactive products migrating at $\sim 60 \mathrm{kDa}$ in size was observed, with marked increase of phosphorylation apparent for the smaller Src form. Phosphorylation of the smaller form was reduced in cells treated with the Src inhibitor, PP1, whereas the larger molecule appeared unaltered.

\section{Downregulation of Fyn Kinase Inhibits IFN $\gamma$-Stimulated Increases in Epithelial Permeability}

Although PP1 is a general Src kinase inhibitor, at $30 \mathrm{nM}$ only the activity of Src family kinase members Lck, Hck or Fyn are effectively blocked. ${ }^{22}$ As Lck and Hck expression is largely restricted to immune cell types, ${ }^{23}$ we assessed whether Fyn participated during IFN $\gamma$ signalling responses in T84 cells. Co-immunoprecipitation studies using Fyn monoclonal antibody showed an increased association of Fyn with the IFN $\gamma$ R2 subunit of the IFN $\gamma$ receptor within $15 \mathrm{~min}$ of IFN $\gamma$ application to T84 cells cultures (Figure 2a). Subsequently, siRNA targeting Fyn was used to assess a role for this Src kinase in IFN $\gamma$ regulation of T84 epithelial monolayer permeability. Anti-Fyn siRNA reduced expression of Fyn protein by T84 cells within $96 \mathrm{~h}$ of transfection, the time determined to be required for T84 monolayers to reach electrical confluence (Figure 2b). Consistent with studies using PP1, specific Fyn knockdown inhibited IFN $\gamma$-stimulated translocation of HRP and E. coli fluxes across T84 monolayers (Figure 2c and d), but did not ameliorate the IFN $\gamma$-induced drop of TER (Figure 2e). Experiments utilizing c-Src siRNA indicated that knockdown of c-Src did not affect IFN $\gamma$-induced increases in translocation of HRP or E. coli HB101 to the significant degree achieved by knockdown of Fyn (data not shown).

\section{IFN $\gamma$ Induces STAT1 and STAT5 Phosphorylation in T84 Cells Independent of Src Activity}

IFN $\gamma$ treatment resulted in STAT1 and STAT5 phosphorylation in both T84 and Caco2 cells (Figure 3a). Analysis of T84 cells revealed that whereas phosphorylation of STAT1 was markedly increased within $30 \mathrm{~min}$ of IFN $\gamma$ exposure, STAT5 phosphorylation was somewhat slower and less robust, peaking at 2 to $3 \mathrm{~h}$ post-IFN $\gamma$. The protracted expression of phosphorylated STAT1 and STAT5 in IFN $\gamma$-treated T84 cells (and STAT5 in Caco2 cells) was not observed in THP-1 cells 

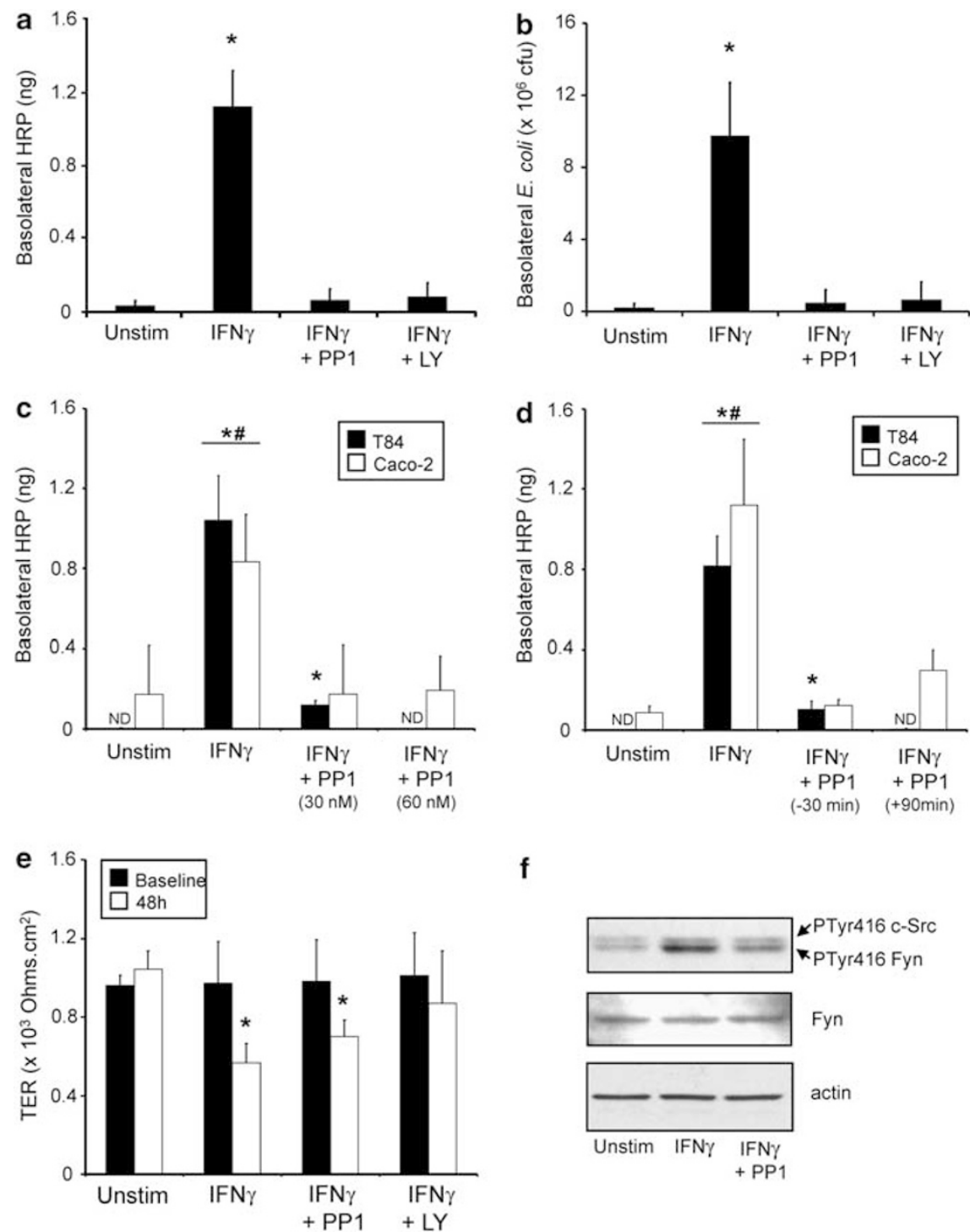

$\mathbf{f}$
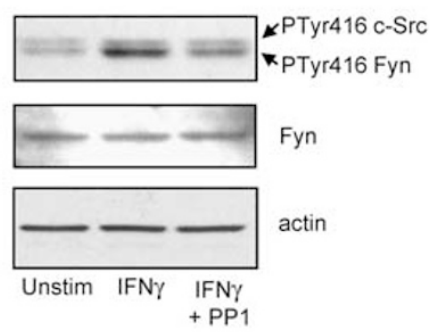

Figure 1 Pharmacological inhibition of Src kinase activity with PP1 $(125 \mathrm{nM})$ administered $90 \mathrm{~min}$ following IFN $\gamma$ stimulation (10 ng/ml; $48 \mathrm{~h}$ total exposure time) attenuates increases in T84 epithelial cell monolayer permeability as gauged by transepithelial flux of (a) horseradish peroxidase (HRP) and (b) E. coli (HB101; $\left.10^{5} \mathrm{CFU}\right)$. (c) Dose response (90 min post-IFN $\gamma$ stimulation) and (d) time dependence of PP1 (125 nM) inhibition of IFN $\gamma$-induced increased flux of HRP across monolayers of the epithelial cell lines T84 (black bars) and Caco2 (white bars). ND, not detected. (a-e); Data are presented as mean \pm s.d.; $n=3$ monolayers/treatment/experiment, representative of three experiments; ${ }^{*} P<0.05$ and ${ }^{\#} P<0.05$ compared with control (Unstim) and PP1 treatment, respectively. (e) The drop in transepithelial resistance (TER) stimulated by IFN $\gamma$ is not significantly affected by PP1. (a, b, e) Effect of inhibition of PI3K with LY294002 (LY: $20 \mu \mathrm{M}$, 90 min post-IFN $\gamma$ stimulation) is shown for comparison. (f) Immunoblots of T84 whole cell extracts showing phosphorylation of Src kinases following $2 \mathrm{~h}$ IFN $\gamma$ stimulation is inhibited by PP1 ( $30 \mathrm{nM}$ ) inhibitor treatment.

differentiated to a macrophage phenotype, where phosphorylation of either molecule was maximal after $15 \mathrm{~min}$ and markedly diminished $2 \mathrm{~h}$ post-IFN $\gamma$ treatment (Figure $3 \mathrm{~b}$ ). The increase in STAT1 and STAT5 phosphorylation observed in T84 epithelia at 2 and $6 \mathrm{~h}$ after IFN $\gamma$ treatment was unaffected by Src kinase inhibition with PP1 or Fyn siRNA (Figure $3 \mathrm{c}$ and $\mathrm{d}$ ).

\section{STAT5 Phosphorylation Is Inhibited by Ablation of STAT1 and Antagonism of JAK Kinase Signalling Activity} STAT1 is mobilized in IFN $\gamma$-responsive cells, whereas activation of STAT5 following exposure to IFN $\gamma$ has, to date, been described in a restricted number of cell types such as hematopoietic cells and mammary epithelia. Earlier pharmacological analyses indicated that STAT1 was not important in IFN $\gamma$-induced reduction in TER across T84 cell monolayers; ${ }^{21}$ however, involvement of STAT1 or STAT5 in the regulation of epithelial macromolecular permeability has not been assessed. STAT1 siRNA effectively reduced STAT1 expression in T84 cells and also caused a reduction in IFN $\gamma$ stimulated expression of IRF-1 (Figure 4a). Knockdown of STAT1 markedly reduced HRP translocation (Figure 4b) but did not affect the IFN $\gamma$-induced drop in TER (Figure 4c), findings consistent with earlier pharmacological analyses. 
a

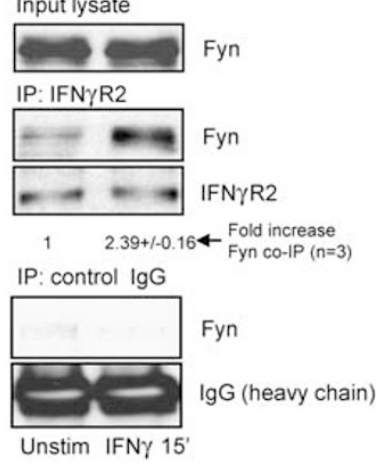

b

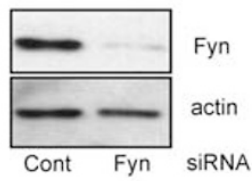

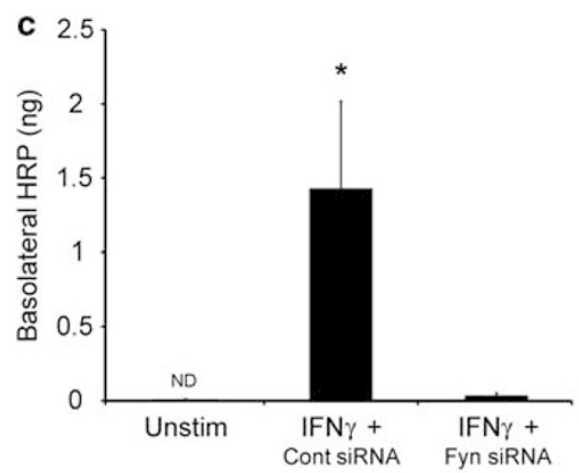
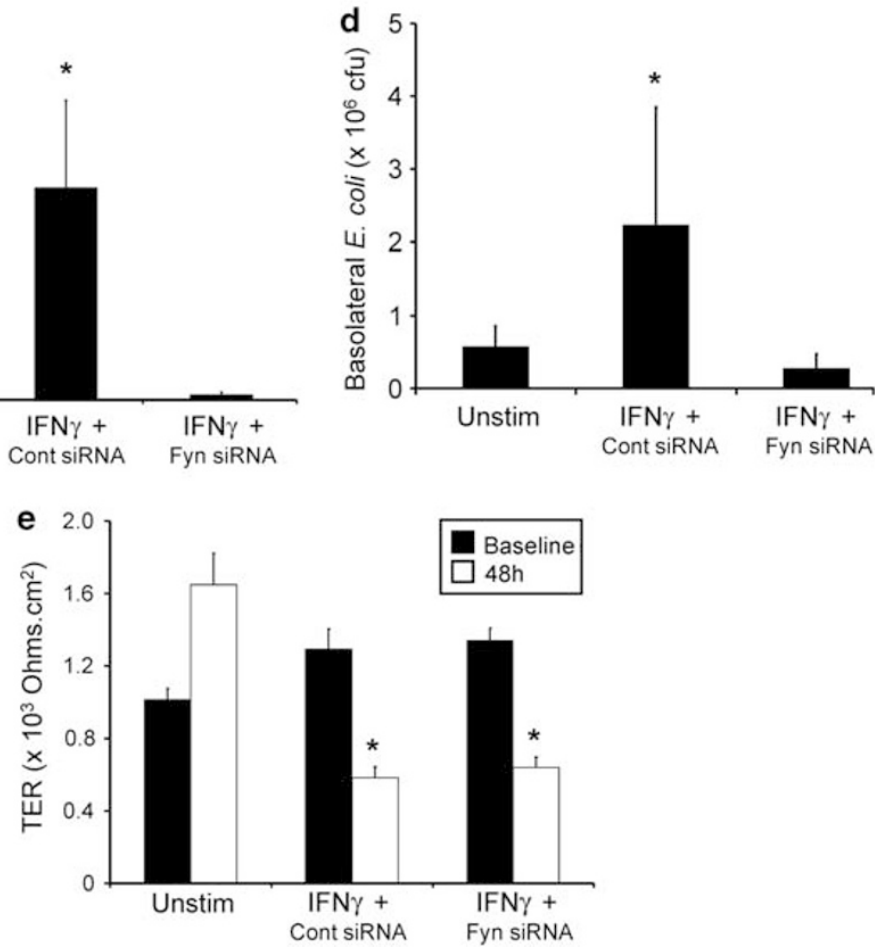

Figure 2 Fyn kinase is a mediator of IFN $\gamma$-induced decreases in T84 epithelial monolayer barrier function. (a) Increased association of Fyn with immunoprecipitated interferon- $\gamma$ receptor (IFN $\gamma \mathrm{R}) 2$ subunit $15 \mathrm{~min}$ following IFN $\gamma$ stimulation is shown. Input lysate levels of Fyn protein as well as an absence of immunoprecipitated Fyn from non-immune lgG control incubations are also shown. Densitometric quantification of Fyn immunoprecipitants was performed using Image J. (b) Reduction of Fyn protein demonstrated by immunoblotting in T84 cells treated $96 \mathrm{~h}$ previous with Fyn siRNA. (c, d) T84 cell monolayers exposed to IFN $\gamma(10 \mathrm{ng} / \mathrm{ml} ; 48 \mathrm{~h})$ and transfected with an irrelevant scrambled (Cont) siRNA displayed significant increases in translocation of $\mathrm{HRP}$ and $E$. coli (HB101) fluxes that were not apparent in monolayers transfected with Fyn siRNA. In contrast, the drop in transepithelial resistance (TER) that accompanies IFN $\gamma$ treatment was not inhibited by Fyn knockdown (e). (c-e) Data represented as mean \pm s.d.; $n=3$ monolayers/treatment/experiment, representative of four experiments; ${ }^{\star} P<0.05$ compared with control (Unstim). ND, not detected.

Notably, STAT1 siRNA treatment of T84 cells also reduced the IFN $\gamma$-evoked phosphorylation of STAT5 (Figure 4d), suggesting a principle requirement of STAT1 during IFN $\gamma$ stimulated biological activity including STAT5 activation and barrier dysfunction. Furthermore, inhibition of Janus kinase (JAK) by treatment of T84 cells with $10 \mu \mathrm{M}$ of the broadspectrum inhibitor AG490 reduced phosphorylation of STAT1 and STAT5 (Figure 4e) and also prevented translocation of HRP across IFN $\gamma$-stimulated monolayer cultures (Figure 4f).
STAT5b and Gab2 Are Required for IFN $\gamma$-Stimulated Increases in Epithelial Permeability and to Interact with PI3K in an IF $\mathbf{\gamma}$-Inducible Complex

We subsequently focused on STAT5b as a mediator of IFN $\gamma$ driven increases of epithelial cell permeability, as it is known to interact with the PI3K pathway in hematopoietic cell lines following growth factor stimulation. Notably, STAT5dependent, PI3K-activating complexes can be induced via coupling to the signalling adaptor Gab2. ${ }^{24,25}$ STAT5b- and Gab2-specific, but not control, siRNAs significantly reduced 
a

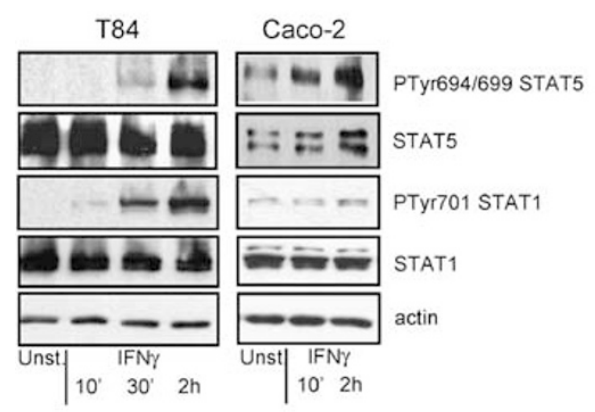

C

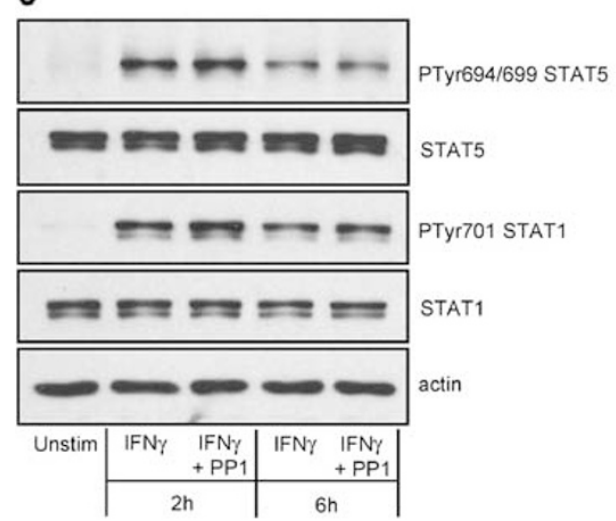

b

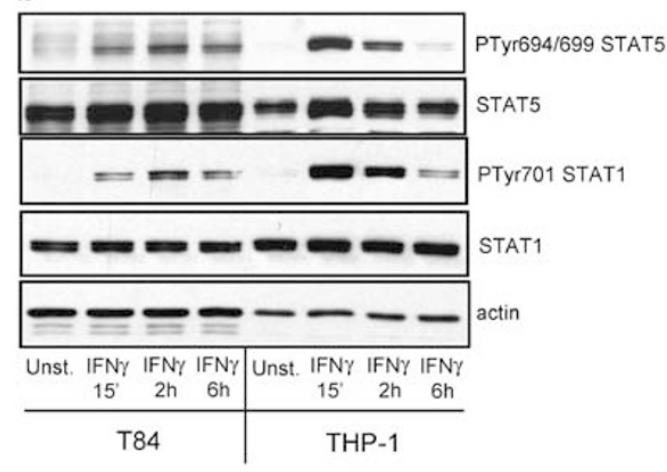

d

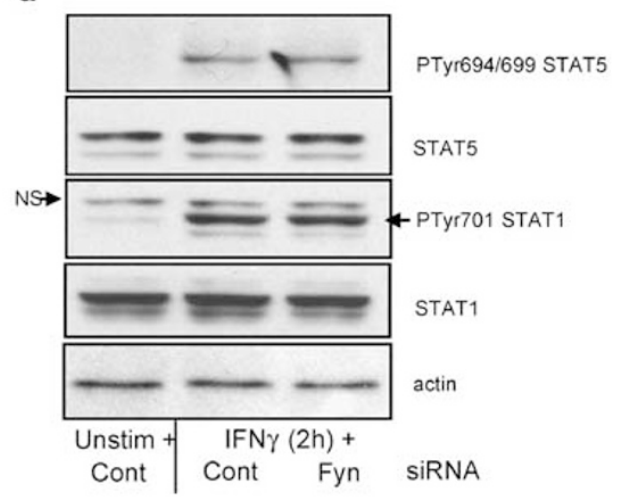

Figure 3 (a) Immunoblotting of whole cell protein extracts from T84 (left panels) and Caco2 (right panels) epithelial cell monolayers show phosphorylation of STAT5 and STAT1 after IFN $\gamma(10 \mathrm{ng} / \mathrm{ml})$ exposure. (b) Different kinetics of STAT1 and STAT5 phosphorylation were induced by IFN $\gamma$ in T84 cells and PMAdifferentiated THP-1 monocytes. Bright-field micrographs ( $\times 20$ magnification) below the immunoblots demonstrate the morphology of THP-1 cells before and following $48 \mathrm{~h}$ of treatment with $20 \mathrm{nM}$ PMA. Src kinase inhibitor PP1 (125 nM) (c) or Fyn siRNA treatment (d) of T84 cells did not inhibit IFN $\gamma$-induced phosphorylation of either STAT5 or STAT1 (images are representative of three experiments). NS, nonspecific bands.

the IFN $\gamma$-induced increase in $E$. coli translocation and transepithelial fluxes of HRP across T84 cell monolayers (Figure $5 \mathrm{a}$ and $\mathrm{b}$ ). Both siRNAs reduced expression of the respective proteins at $96 \mathrm{~h}$ after transfection (Figure $5 \mathrm{c}$ ). Consistent with experiments utilizing the Src inhibitor PP1 or Fyn siRNA, the drop in T84 monolayer TER evoked by IFN $\gamma$ was affected by knockdown of neither STAT5b nor Gab2 (data not shown). Furthermore, IFN $\gamma$ activation of Fyn (ie, phosphorylated on Tyr 416) in the cell membrane was markedly reduced by siRNA against both Fyn and STAT5b (Figure 5d).

IFN $\gamma$ induces $\mathrm{PI} 3 \mathrm{~K}$ activity as measured by $\mathrm{PIP}_{3}$ formation (Figure 6a) and phosphorylation of the PI3K-regulated serine/ threonine kinase Akt (Figure 6b), which was inhibited by LY2940. Immune complexes precipitated with anti-STAT5b show increased association of Gab2 and PI3K p $85 \alpha 6 \mathrm{~h}$ postIFN $\gamma$ stimulation (Figure 6c). Reciprocal blots following IP with anti-PI3K p $85 \alpha$ antibodies revealed increased association with STAT5b and Gab2 in response to IFN $\gamma$ (data not shown).

\section{Fyn Kinase Is Required for Formation of STAT5b/ PI3K(P85 $\alpha)$ Complexes Stimulated by IFN $\gamma$ in T84 Cells}

PI3K activation in response to select stimuli can be dependent upon the activity of Src kinases including Fyn; ${ }^{26}$ thus, we assessed whether Fyn was required for IFN $\gamma$-stimulation of PI3K activity in T84 cells. Fyn knockdown reduced the phosphorylation of Gab2 (Tyr452, contained within a putative YVPM p $85 \alpha$ binding site) evoked by IFN $\gamma$ stimulation (Figure 7a). Akt phosphorylation observed $6 \mathrm{~h}$ after IFN $\gamma$ treatment was also reduced by Fyn siRNA treatment; both findings were corroborated by treatment with PP1, given 90 min after IFN $\gamma$ treatment (Figure $7 \mathrm{~b}$ ).

Subsequent co-immunoprecipitation studies revealed that association of STAT5b and Gab2 with $\mathrm{p} 85 \alpha$ at $6 \mathrm{~h}$ post-IFN $\gamma$ stimulation was reduced by Fyn-specific siRNA (Figure 7c), findings that were reproduced in PP1-treated T84 monolayers (Figure $7 \mathrm{~d}$ ).

\section{Neither PI3K Inhibition Nor Fyn Knockdown Interfere with STAT1 Signalling in T84 Epithelia}

Initial studies showed that Src kinase inhibition with PP1 or Fyn siRNA did not appreciably affect IFN $\gamma$-induced STAT1 phosphorylation in T84 cells (Figure $4 \mathrm{~b}$ and $\mathrm{c}$ ). Therefore, we assessed the effects of Src inhibition upon expression of a STAT1-dependent gene product, IRF-1. Increased IRF-1 protein expression was observed by $6 \mathrm{~h}$ post-IFN $\gamma$ stimulation and was unaffected by treatment with PP1 (Figure 8a) or 
a

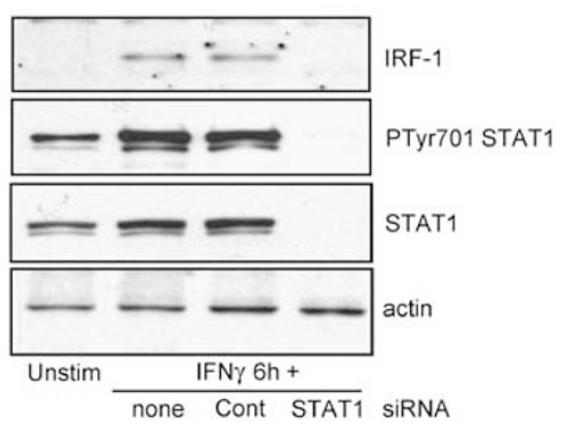

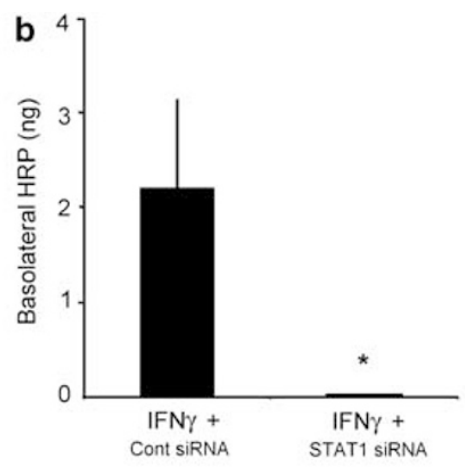

d
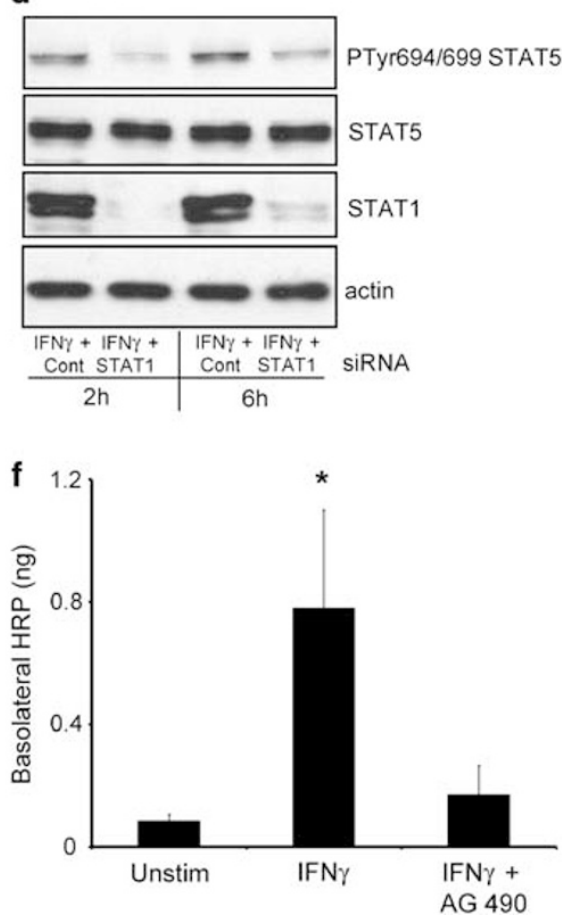

Figure 4 STAT1 is central to IFN $\gamma$-stimulated T84 epithelial responses. (a) siRNA against STAT1 reduces STAT1 synthesis and consequently IFN $\gamma$ (10 $\mathrm{ng} / \mathrm{ml}$ ) of IRF-1 protein and also (b) blocks IFN $\gamma$-induced increases in HRP translocation (measured $48 \mathrm{~h}$ post-treatment), but not the drop in TER. (c) Data are presented as mean \pm s.d.; $n=3$ monolayers/treatment/experiment, representative of two experiments; ${ }^{*} P<0.05$ compared with scrambled siRNA control (Cont siRNA) and ${ }^{\#} P<0.05$ compared with control and matched baseline data. (d) STAT1 siRNA reduced IFN $\gamma$-induced phosphorylation of STAT5 as revealed by immunoblotting (siRNA transfection of T84 was conducted $48 \mathrm{~h}$ before stimulation). (e, $\mathbf{f}$ ) The general JAK kinase inhibition (10 $\mu \mathrm{M}$ ) reduces IFN $\gamma$-induced phosphorylation of STAT1 and STAT5 (PP1 does not) and also significantly reduces the increased transepithelial flux of HRP (mean \pm s.d.; $n=3$ monolayers/ treatment/experiment, representative of four experiments; ${ }^{*} P<0.05$ compared with control unstimulated (Unstim) monolayers).

the pan-PI3K inhibitor LY294002 $(20 \mu \mathrm{M})$ (Figure $8 \mathrm{~b}$ ). Furthermore, the induction and release of the IFN $\gamma$ STAT1-dependent cytokine, IP-10, was not inhibited in T84 cells co-treated with LY294002 (control $=0.06 \pm 0.02$, $\mathrm{IFN} \gamma$ treated $=13.7 \pm 0.5$ and $\mathrm{IFN} \gamma+\mathrm{LY} 294002$ treated $=$ $11.9 \pm 1.6 \mathrm{ng} / \mathrm{ml} ; n=3)$.

\section{DISCUSSION}

Analyses of human enteric epithelial cell lines and murine models of gut dysfunction reveal that IFN $\gamma$ can significantly increase epithelial permeability. ${ }^{27,28}$ As the intestinal epithelium is the primary interface between the body and the external environment, IFN $\gamma$-induced decreases in epithelial barrier function would allow potentially dangerous stimuli (eg, low-grade pathogens, commensal bacteria, unprocessed antigen) into the mucosa that could precipitate or exaggerate existing inflammation. Consequently, knowledge of the epithelial intracellular signalling events engaged by IFN $\gamma$ that reduce barrier function could allow for the formulation of therapies to limit the increases in gut permeability, with the advantage of leaving the impact of IFN $\gamma$ on immune cells intact.

The ability of IFN $\gamma$ to increase epithelial permeability was demonstrated $\sim 20$ years ago. ${ }^{27}$ Since then, substantial data have accumulated showing that IFN $\gamma$ increases epithelial paracellular permeability (evidenced by increased flux of 

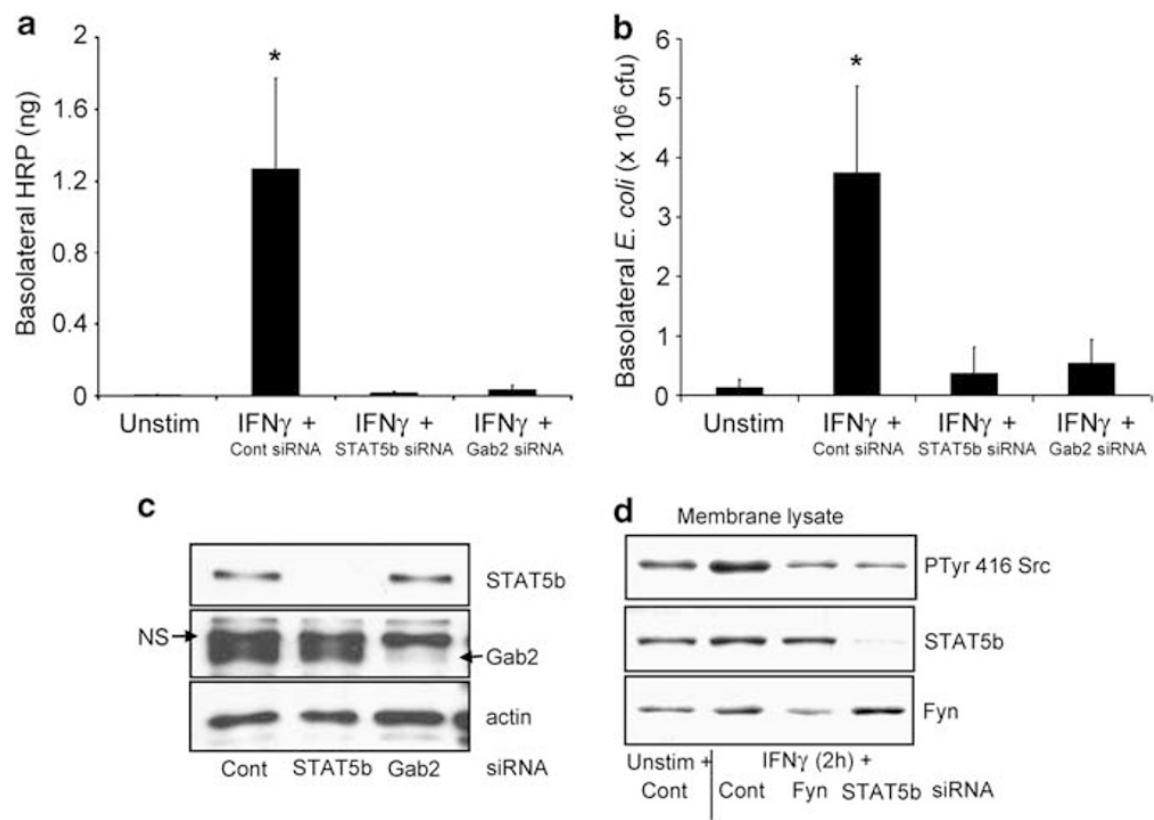

Figure 5 STAT5b and Gab2 are required to observe IFN $\gamma$-induced increases in T84 epithelial monolayer macromolecular permeability. The bar graphs in (a, b) show that IFN $\gamma(10 \mathrm{ng} / \mathrm{ml} ; 48 \mathrm{~h})+$ scrambled siRNA (Cont) resulted in significant increases in HRP fluxes and E. coli (HB101) translocation across confluent T84 monolayers that was blocked by use of STAT5b and Gab2 targeting siRNA (mean \pm s.d.; $n=3$ monolayers/treatment/experiment, representative of four experiments; ${ }^{*} P<0.05$ compared with control (Unstim); starting TER in these experiments ranged $\left.1200-1600 \mathrm{Ohms} / \mathrm{cm}^{2}\right)$. (c) Reduced expression of STAT5b and Gab2 protein in whole cell extracts of T84 cells treated with specific targeting siRNAs that was not observed in cells treated with an irrelevant scrambled (Cont) siRNA. (d) siRNA targeting Fyn or STAT5b reduced IFN $\gamma$-stimulated $(2 \mathrm{~h})$ membrane-associated activated Fyn in T84 cells. (c, d) Images are representative of three experiments. NS, nonspecific bands.

small inert molecules and loss or internalization of TJ proteins), that a considerable time lag (24-48 h) exists between IFN $\gamma$ exposure and reduced epithelial integrity and that apoptosis is not a major cause of the increased epithelial permeability. ${ }^{6,29}$ However, there remains a lack of information on the intracellular signalling events proximal to the IFN $\gamma \mathrm{R}$ that induce IFN $\gamma$-mediated increases of epithelial permeability.

JAK/STAT1 signalling is recognized as an important component of IFN $\gamma$-stimulated gene expression. ${ }^{30}$ STAT1independent activities of IFN $\gamma$ have been described and PI3K has emerged as an important alternative signalling molecule that may also cross-talk with the JAK/STAT1 pathway. ${ }^{31}$ Earlier pharmacological analysis, ${ }^{21}$ corroborated by current siRNA studies, show that STAT1 does not have a significant role in the IFN $\gamma$-induced decreases in TER of monolayers of T84 cells. In contrast, STAT1 knockdown reduced IFN $\gamma$ driven increases in the translocation of HRP, indicating a role in the control of the barrier function to macromolecules, and is consistent with the central activity that STAT1 has in IFN $\gamma$ signal transduction. However, ablation of STAT1 in epithelial cells would have a huge impact on their function, and thus we sought to explore a tangential pathway that would link the IFN $\gamma \mathrm{R}$ to the PI3K pathway, which has been shown to mediate IFN $\gamma$-induced increases in epithelial permeability. ${ }^{10,12,32}$
Our data presented in this study suggest a novel mechanism for IFN $\gamma$-mediated activation of PI3K, involving interactions between STAT5b, Gab2 and the Src kinase Fyn (summarized in Figure 9). Whereas STAT5b can be phosphorylated in monocyte and T-cell lines in response to IFN $\gamma,{ }^{33}$ here we show activation of STAT5, a previously undocumented activity of IFN $\gamma$ in intestinal epithelial cells. This STAT5 phosphorylation in response to IFN $\gamma$ was inhibited by use of the broad-spectrum JAK kinase inhibitor, AG490, and was also STAT1 dependent, being significantly reduced by STAT1-specific siRNA. These findings suggest a crucial requirement for STAT1 in transducing cellular responses to IFN $\gamma$, corroborating the view presented by others. ${ }^{34}$ Moreover, siRNA knockdown of STAT5b (and the use of AG409) resulted in a restoration of T84 cell barrier integrity, preventing IFN $\gamma$-stimulated translocation of both macromolecules (HRP) and microbes (E. coli HB101), comparable with that achieved by pharmacological inhibition of PI3K activity. Gab2 is a scaffolding adaptor previously shown to mediate STAT5-dependent PI3K activation in hematopoietic cell lines. ${ }^{25}$ Aside from a putative STAT5-binding site, Gab2 possesses multiple protein-binding motifs such as Src homology (SH)2 and $\mathrm{SH} 3$ domains, proline-rich repeats suitable for interaction with the p $85 \alpha$ moiety of PI3K, as well as multiple tyrosine phosphorylation sites that may be targeted by kinases including Src family members. ${ }^{35,36}$ Use of 
a

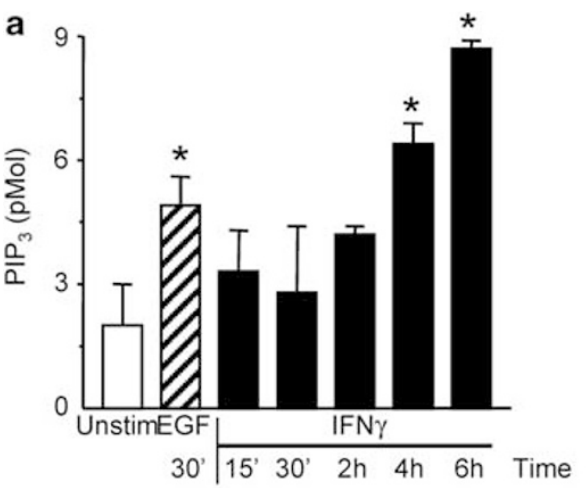

C

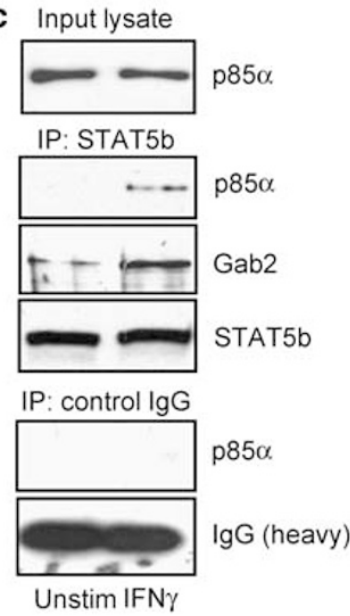

b

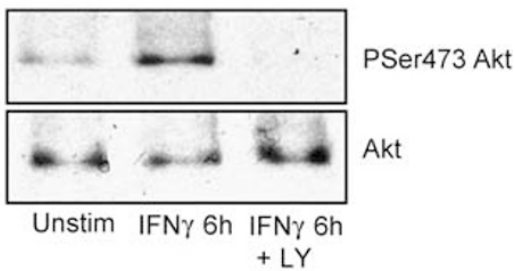

Figure 6 Treatment with IFN $\gamma$ evokes formation of a STAT5b/Gab2/PI3K(p85 $\alpha$ ) complex in T84 epithelia. (a) Measurement of PIP 3 and (b) phosphorylation of AKT following IFN $\gamma(10 \mathrm{ng} / \mathrm{ml}$ ) indicates activation of PI3K (epidermal growth factor (EGF) at $10 \mathrm{ng} / \mathrm{ml}$; mean \pm s.d. of three epithelial preparations/time point; ${ }^{*} P<0.05$ compared with control (Cont); immunoblotting of phosphor-Ser473 Akt at $6 \mathrm{~h}$ post-IFN $\gamma$ treatment; LY denotes co-treatment of IFN $\gamma$-stimulated cultures with $20 \mu \mathrm{M}$ of the PI3K inhibitor, LY2940). (c) Representative immunoprecipitations using STAT5b antibody show increased association of STAT5b/Gab2/PI3K(p85 $\alpha)$ at $6 \mathrm{~h}$ after treatment with IFN $\gamma$. Input and nonimmune controls are shown.

Gab2 siRNA prevented the IFN $\gamma$-stimulated increase in T84 monolayer permeability, and knockdown of either Gab2 or STAT5 reduced phosphorylation of the $\mathrm{PI} 3 \mathrm{~K}(\mathrm{p} 85 \alpha)$, suggesting that interaction of Gab2 and STAT5 is required for activation of PI3K following exposure to IFN $\gamma$.

The Src kinases are expressed variably across tissue and cell types, with robust expression of the Fyn, Yes and c-Src isoforms in most cell types including epithelia. Of relevance to our study, Src kinases have been implicated as activators of STAT5 in studies of transformed breast epithelial cell lines. ${ }^{37-39}$ Several Src isoforms can interact with adhesion molecules including integrins ${ }^{40}$ and E-cadherin, ${ }^{41}$ potentially having a role in cell-cell interactions. Src activity has been implicated in the phosphorylation of occludin and its interaction with $\mathrm{ZO}-1,{ }^{42,43}$ and in IFN $\gamma$ - and oxidative stressstimulated reductions in active $\mathrm{Cl}^{-}$secretion. ${ }^{18,20}$ Fyn kinase colocalizes with and phosphorylates both p120-catenin and $\beta$-catenin, critical constituents of the cadherin-catenin complex within epithelial cell adherens junctions. ${ }^{44,45}$ Furthermore, Fyn has been implicated during enteropathogenic $E$. coli infection, complexing with the E. coli receptor in activation of pedestal formation. ${ }^{46,47}$ Thus, a putative role for Fyn as a potential mediator of cytokine-stimulated barrier permeability merited further exploration.

Ablation of Fyn activity by either PP1 ( $30 \mathrm{nM}$ is highly selective for inhibition of Fyn kinases) or siRNA did not affect the ability of IFN $\gamma$ to reduce TER, nor did it appreciably affect STAT1 or STAT5 phosphorylation, but it almost completed abolished the concomitant increased transcytosis of HRP and E. coli. This suggests recruitment of Fyn after STAT activation and this is substantiated by IP showing Fyn in complex with IFN $\gamma \mathrm{R} 2$, the major signalling component of the IFN $\gamma \mathrm{R}$, within $15 \mathrm{~min}$ of IFN $\gamma$ addition to T84 epithelia. Moreover, when applied after IFN $\gamma$, PP1 still reduced the barrier defect and this is compatible with the delay in obvious PI3K activation following exposure to IFN $\gamma$. Inhibition of Fyn activity reduced phosphorylation of the PI3K-dependent kinase Akt, indicating a functional interaction between Fyn and PI3K. Indeed, blockade of Fyn resulted in a degree of inhibition of IFN $\gamma$-induced increases in macromolecular permeability that was not significantly different from that achieved by LY294002 inhibition of PI3K activity. These data 
a

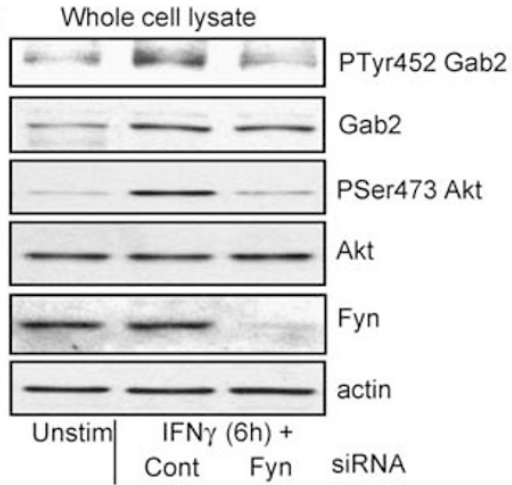

C

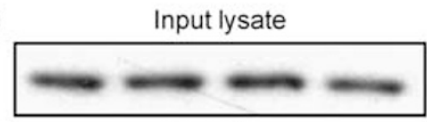

IP: $\mathrm{p} 85 \alpha$

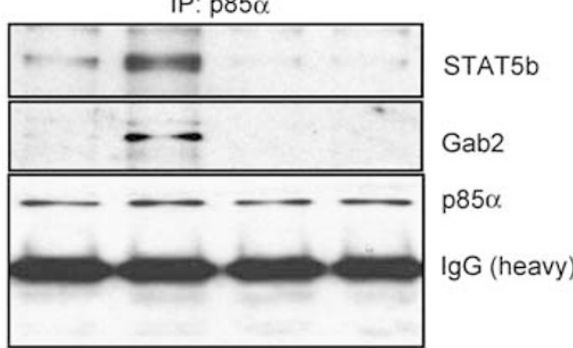

IP: p $85 \alpha /$ IB: P-Tyr(4G10)

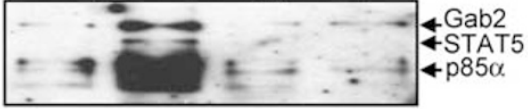

IP: control IgG

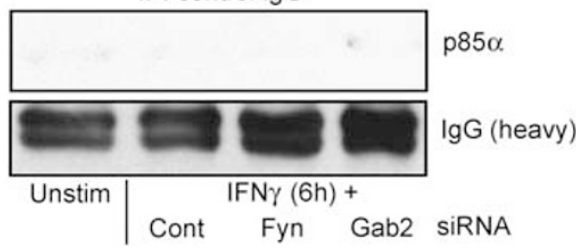

b

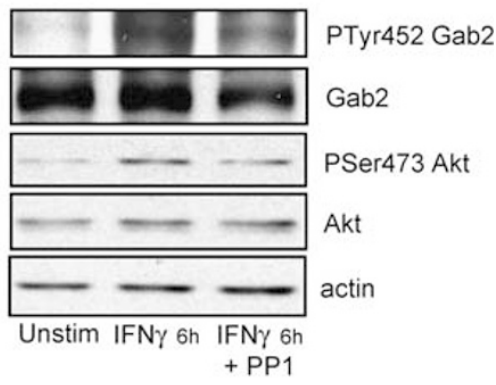

d

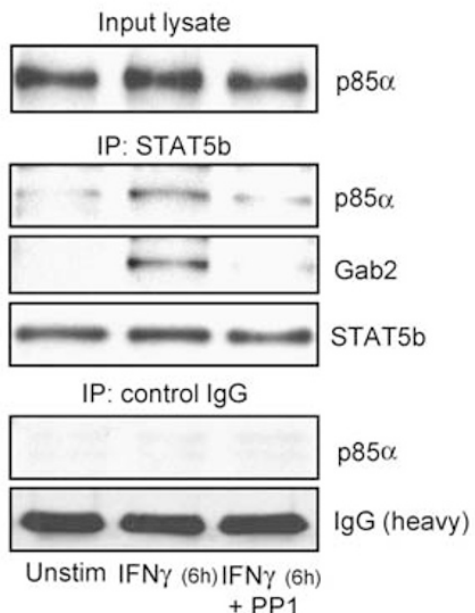

$+\mathrm{PP} 1$

Figure 7 (a) Immunoblots of T84 epithelial cell whole cell lysates demonstrate Gab2 was phosphorylated following $6 \mathrm{~h}$ of IFN $\gamma$ stimulation and this was inhibited by transfection of Fyn-targeting siRNA. Levels of IFN $\gamma$-stimulated phospho-Akt were also reduced by Fyn siRNA. (b) IFN $\gamma$-stimulated increases of Gab2 and Akt phosphorylation were reduced by the Src inhibitor PP1 (125 nM, 90 min post-stimulation). (c) Treatment of T84 cells with Fyn or Gab2 siRNA reduces PI3K $(\mathrm{p} 85 \alpha)$ and Gab2 interaction with STAT5b at $6 \mathrm{~h}$ after treatment with IFN $\gamma(10 \mathrm{ng} / \mathrm{ml}$; images are representative of two experiments). Fyn- and Gab2-siRNA-treated cells demonstrated reduced IFN $\gamma$-stimulated tyrosine phosphorylation of products putatively identified as STAT5, Gab2 and p85. (d) Reduced association of STAT5b with p85 $\alpha$ and Gab2 in STAT5b co-immunoprecipitates following IFN $\gamma$ stimulation (6h) in the presence of PP1. Input and nonimmune controls are shown.

indicate that changes in TER are not fully representative of epithelial barrier function and suggest, but do not prove, a Fyn-PI3K axis in the regulation of macromolecule flux across enteric epithelia.

Furthermore, we observed Gab2 phosphorylation and recruitment to STAT5b/PI3K $(\mathrm{p} 85 \alpha)$ complexes in an IFN $\gamma$ inducible, Fyn-dependent manner in T84 cells. Coimmunoprecipitations following IFN $\gamma$ treatment indicated physical association between PI3K(p85 $\alpha$ ), STAT5 and Gab2 and that this was disrupted by Fyn knockdown. These data are strong evidence of Fyn lying upstream of PI3K during IFN $\gamma$ signalling responses that regulate epithelial permeability and suggest a pivotal role for STAT5b, Gab2 and Fyn kinase in the mediation of IFN $\gamma$-evoked increases in the transcytosis of macromolecules and microbes across an enteric epithelium. The divergence in the ability of siRNA knockdown of Gab2 and STAT5 and inhibition of Fyn activity in IFN $\gamma$ control of TER and macromolecule transcytosis is noteworthy and suggest that at least a portion of the increased HRP flux and E. coli transcytosis is dependent on a transcellular pathway. Others have shown that IFN $\gamma$ promoted the transcytosis of E. coli (strain C25) across Caco2 epithelial monolayers and that this preceded any drop in TER. ${ }^{9}$ Having uncovered evidence of Fyn-PI3K interaction, it is interesting 
a
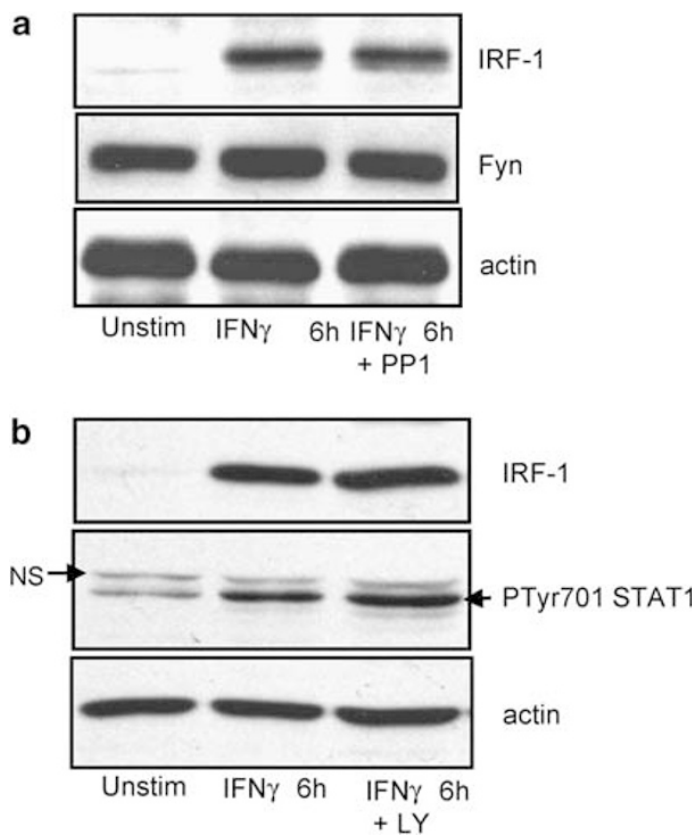

Figure 8 (a) Immunoblots of T84 epithelial cell whole cell extracts show that the treatment with Src kinase inhibitor PP1 $(125 \mathrm{nM})$ did not decrease the expression of the IFN $\gamma$-responsive gene IRF-1 following $6 \mathrm{~h}$ of treatment with IFN $\gamma(10 \mathrm{ng} / \mathrm{ml})$. (b) IRF-1 expression induced by IFN $\gamma$ was not decreased by treatment with the PI3K inhibitor LY294002 $(20 \mu \mathrm{M})$. NS, nonspecific band. that PI3K inhibition blocked the IFN $\gamma$-induced drop in TER, whereas Src inhibition with PP1 did not. This may reflect differences in the efficacy of the pharmacologics but could also reflect differences in the signalling pathways that govern paracellular and transcellular permeability. Much remains to be done to precisely elucidate the IFN $\gamma$ signalling events that control epithelial barrier function, and whereas others have focused on defining TJ protein and cytoskeletal changes, ${ }^{5-8}$ the present investigation is in accordance with IFN $\gamma$ modulation of epithelial endocytosis and transcellular permeability. ${ }^{10}$

The delay in PI3K activity relative to initial STAT phosphorylation is intriguing and suggests mobilization of temporally and spatially distinct signalling pathways, a hypothesis supported by data showing that in T84 cells, neither Src kinase nor PI3K inhibition affected STAT1dependent immune activities (IRF-1 expression and IP-10 secretion). It is also noteworthy that STAT1 and STAT5 activation is slower and reduced in magnitude in epithelia compared with macrophages (Figure $4 \mathrm{~b}$ ) and this could contribute to a delayed accumulation of other intracellular signals in the enterocyte, and ultimately to the $24-48 \mathrm{~h}$ lag period observed between IFN $\gamma$ treatment and increases in T84 epithelial monolayer permeability. These findings suggest that the immunostimulatory and barrier effects of
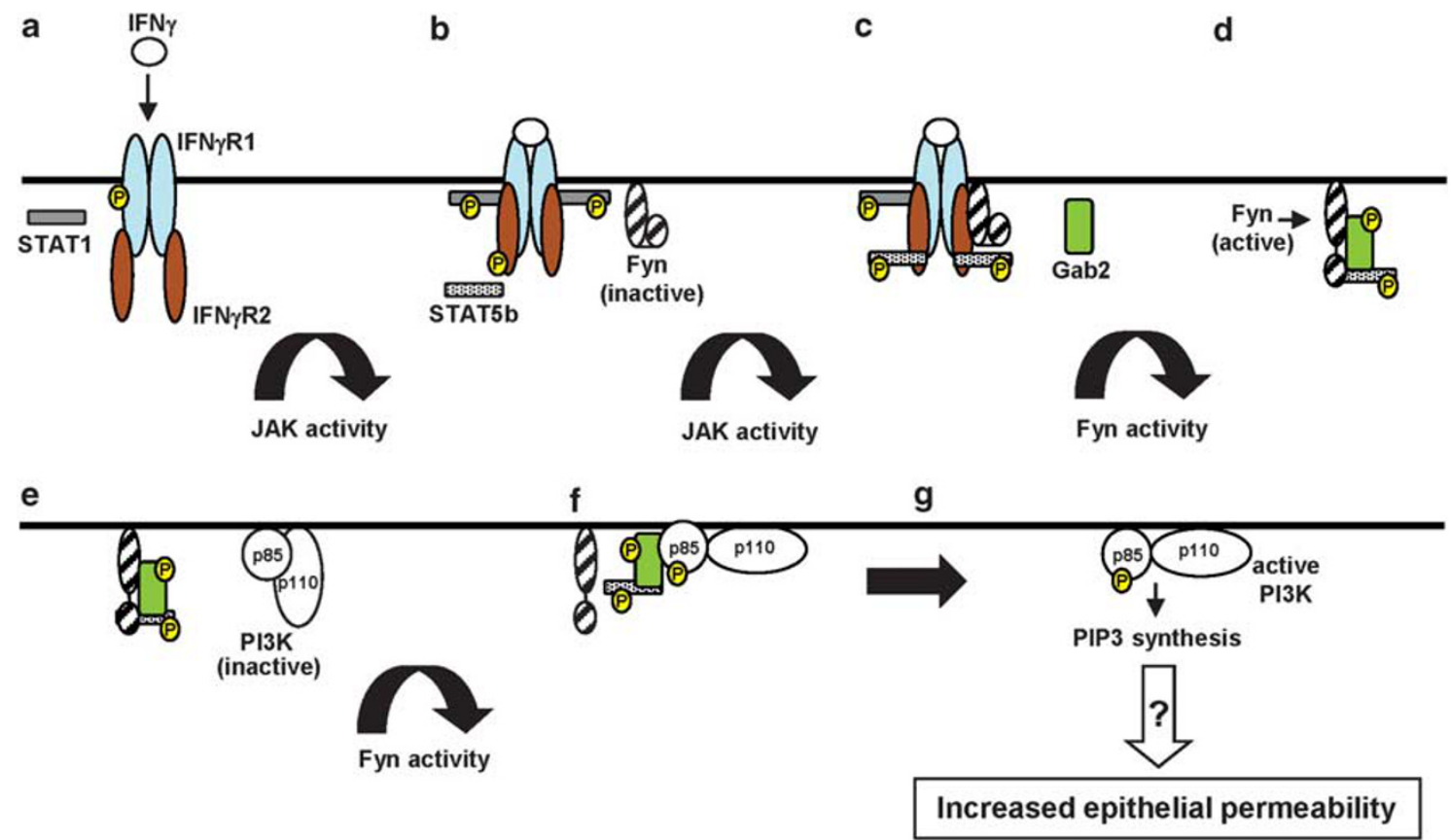

Figure 9 Proposed model of signalling at the IFN $\gamma R$ that control enteric epithelial macromolecular permeability. (a) Ligation of the IFN $\gamma R$ stimulates JAK-dependent phosphorylation of IFN $\gamma$ R1 resulting in rapid STAT1 recruitment and phosphorylation (b) that allows for a JAK-dependent recruitment and phosphorylation of STAT5b at IFN $\gamma$ R2 along with Fyn Src kinase (c). The Gab2 scaffolding protein is recruited to STAT5b and phosphorylated via Fyn, leading to a STAT5b/Gab2 complex that may remain associated with Fyn (d). Within 2-6h, PI3K (p85 recruitment/regulatory domain and p110 catalytic domain) is recruited to Gab2 (e), and p85 phosphorylation, possibly via Fyn, relieves inhibition of the catalytic subunit (f). The active PI3K is then available to mobilize membrane lipids and a putative host of downstream enzymes that can lead to decreased epithelial barrier function (g). $P$, phosphorylated residue. 
IFN $\gamma$ can be targeted independently. Deficiencies in IFN $\gamma$ R, STAT1 or IRF-1 expression can all result in increased susceptibility to infectious organisms, particularly at mucosal surfaces. ${ }^{48}$ Thus, the ability to target the STAT5b/Gab2/Fyn/ PI3K pathway in enteric epithelia to preserve the barrier function of the epithelium, while not interfering with the ability of IFN $\gamma$ to mobilize STAT1-dependent immune events in immune and stromal cells, could be an advantageous therapeutic approach.

In conclusion, using T84 cells as model gut epithelium, data are presented illustrative of a STAT5b/Gab2/Fyn/PI3K interaction that is dependent of STAT1 (perhaps as a prerequisite to allow STAT5/IFN $\gamma \mathrm{R}$ interaction) and operates in parallel with STAT1 signal transduction events. When this pathway is inhibited, the ability of IFN $\gamma$ to decrease the barrier function of epithelial monolayers, as measured by macromolecule and microbe transcytosis, was reduced. Such a specific intervention in the activity of IFN $\gamma$ at the level of the epithelium in treating gut disease would have the concomitant advantage of preserving immunostimulatory activities of IFN $\gamma$ on structural and immune cell populations.

\section{ACKNOWLEDGEMENTS}

This work was funded by a Canadian Institutes of Canada (CIHR) research grant to DM McKay (MOP-84289). D Smyth is funded by CIHR/Canadian

Association of Gastroenterology/Crohn's and Colitis Foundation of Canada and Alberta Heritage Foundation for Medical Research (AHFMR) postdoctoral Fellowships. DM McKay is an AHFMR Scientist and holds a Canada Research Chair (Tier 1) in Intestinal Immunophysiology.

\section{DISCLOSURE/CONFLICT OF INTEREST}

The authors declare no conflict of interest.

1. Turner JR. Intestinal mucosal barrier function in health and disease. Nat Rev Immunol 2009;9:799-809.

2. Uhlig HH, Powrie F. Mouse models of intestinal inflammation as tools to understand the pathogenesis of inflammatory bowel disease. Eur J Immunol 2009;39:2021-2026.

3. Mankertz J, Schulzke JD. Altered permeability in inflammatory bowel disease: pathophysiology and clinical implications. Curr Opin Gastroenterol 2007;23:379-383.

4. Camoglio L, Te Velde AA, Tigges AJ, et al. Altered expression of interferon- $\gamma$ and interleukin- 4 in inflammatory bowel disease. Inflamm Bowel Dis 1998;4:285-290.

5. Beaurepaire C, Smyth D, McKay DM. Interferon- $\gamma$ regulation of intestinal epithelial permeability. J Interferon Cytokine Res 2009;23: 133-143.

6. Bruewer $\mathrm{M}$, Utech $\mathrm{M}$, Ivanov $\mathrm{Al}$, et al. Interferon- $\gamma$ induces internalization of epithelial tight junction proteins via a macropinocytosis-like process. FASEB J 2005;19:923-929.

7. Youakim A, Ahdieh M. Interferon- $\gamma$ decreases barrier function in T84 cells by reducing ZO- 1 levels and disrupting apical actin. Am J Physiol Gastrointestin Physiol 1999;276:G1279-G1288.

8. Wang $F$, Graham WV, Wang $Y$, et al. Interferon- $\gamma$ and tumor necrosis factor- $\alpha$ synergize to induce intestinal epithelial barrier dysfunction by up-regulating myosin light chain kinase expression. Am J Pathol 2005;166:409-419.

9. Clark E, Hoare C, Tanianis-Hughes J, et al. Interferon- $\gamma$ induces translocation of commensal Escherichia coli across gut epithelial cells via a lipid raft-mediated process. Gastroenterology 2005;128: 1258-1267.

10. McKay DM, Watson JL, Wang A, et al. Phosphatidylinositol $3^{\prime}$-kinase is a critical mediator of interferon- $\gamma$-induced increases in enteric epithelial permeability. J Pharm Exp Ther 2007;320:1013-1022.
11. Stark GR, Kerr IM, Williams BR, et al. How cells respond to interferons. Annu Rev Biochem 1998;67:227-264.

12. Scharl M, Paul G, Barrett $K E$, et al. AMP-activated protein kinase mediates the interferon- $\gamma$-induced decrease in intestinal epithelial barrier function. J Biol Chem 2009;284:27952-27963.

13. Nguyen $\mathrm{H}$, Ramana CV, Bayes J, et al. Roles of phosphatidylinositol 3kinase in interferon-gamma-dependent phosphorylation of STAT1 on serine 727 and activation of gene expression. J Biol Chem 2001;276:33361-33368.

14. Brown MT, Cooper JA. Regulation, substrates and functions of src. Biochim Biophys Acta 1996;1287:121-149.

15. Hayakawa F, Naoe T. SFK-STAT pathway: an alternative and important way to malignancies. Ann NY Acad Sci 2006;1086:213-222.

16. Jin W, Yun C, Jeong J, et al. C-Src is required for tropomyosin receptor kinase C (TrkC)-induced activation of the phosphatidylinositol 3-kinase (PI3K)-AKT pathway. J Biol Chem 2008;283:1391-1400.

17. Xing J, Zhang $Z$, Mao $H$, et al. Src regulates cell cycle protein expression and renal epithelial cell proliferation via PI3K/Akt signaling-dependent and -independent mechanisms. Am J Physiol Renal Physiol 2008; 295:F145-F152.

18. Uribe JM, McCole DF, Barrett KE. Interferon- $\gamma$ activates EGF receptor and increases TGF- $\alpha$ in T84 cells: implications for chloride secretion. Am J Physiol Gastrointest Liver Physiol 2002;283:G923-G931.

19. Saksena S, Gill RK, Tyagi $\mathrm{S}$, et al. Role of Fyn and PI3K in $\mathrm{H}_{2} \mathrm{O}_{2}$-induced inhibition of apical $\mathrm{Cl}^{-} / \mathrm{OH}$ - exchange activity in human intestinal epithelial cells. Biochem J 2008;416:99-108.

20. Chappell AE, Bunz M, Smoll E, et al. Hydrogen peroxide inhibits $\mathrm{Ca}^{2+}$ dependent chloride secretion across colonic epithelial cells via distinct kinase signaling pathways and ion transport proteins. FASEB J 2008;22:2023-2036.

21. Watson JL, Ansari $\mathrm{S}$, Cameron $\mathrm{H}$, et al. Green tea polyphenol (-)epigallocatechin gallate blocks epithelial barrier dysfunction provoked by IFN- $\gamma$ but not by IL-4. Am J Physiol Gastrointest Liver Physiol 2004;287:G954-G961.

22. Hanke JH, Gardner JP, Dow RL, et al. Discovery of a novel, potent, and Src family-selective tyrosine kinase inhibitor. Study of Lck- and FynTdependent T cell activation. J Biol Chem 1996;271:695-701.

23. Brickell PM. The p60c-src family of protein-tyrosine kinases: structure, regulation, and function. Crit Rev Oncog 1992;3:401-446.

24. Santos SC, Lacronique V, Bouchaert I, et al. Constitutively active STAT5 variants induce growth and survival of hematopoietic cells through a PI 3-kinase/Akt dependent pathway. Oncogene 2001;20:2080-2090.

25. Nyga R, Pecquet C, Harir N, et al. Activated STAT5 proteins induce activation of the PI 3-kinase/Akt and Ras/MAPK pathways via the Gab2 scaffolding adapter. Biochem J 2005;390:359-366.

26. Karnitz LM, Sutor SL, Abraham RT. The Src-family kinase, Fyn, regulates the activation of phosphatidylinositol 3-kinase in an interleukin 2-responsive T cell line. J Exp Med 1994;179:1799-1808.

27. Madara JL, Stafford J. Interferon- $\gamma$ directly affects barrier function of cultured intestinal epithelial monolayers. J Clin Invest 1989;83: 724-727.

28. Ito R, Shin-Ya M, Kishida $T$, et al. Interferon- $\gamma$ is causatively involved in experimental inflammatory bowel disease in mice. Clin Exp Immunol 2006;146:330-338.

29. Utech M, Ivanov Al, Samarin SN, et al. Mechanism of IFN- $\gamma$-induced endocytosis of tight junction proteins: myosin II-dependent vacuolarization of the apical plasma membrane. Mol Biol Cell 2005; 16:5040-5052.

30. Bach EA, Aguet $\mathrm{M}$, Schreiber RD. The IFN- $\gamma$ receptor: a paradigm for cytokine receptor signaling. Annu Rev Immunol 1997;15:563-591.

31. Ramana CV, Gil MP, Schreiber RD, et al. Stat1-dependent and independent pathways in IFN- $\gamma$-dependent signaling. Trends Immunol 2002;23:96-101.

32. McKay DM, Botelho F, Ceponis PJ, et al. Superantigen immune stimulation activates epithelial STAT- 1 and PI3-K: PI3-K regulation of permeability. Am J Physiol Gastrointest Liver Physiol 2000;279: G1094-G1103.

33. Meinke A, Barahmand-Pour F, Wohrl S, et al. Activation of different Stat5 isoforms contributes to cell-type-restricted signaling in response to interferons. Mol Cell Biol 1996;16:6937-6944.

34. Woldman I, Varinou L, Ramsauer K, et al. The Stat1 binding motif of the interferon- $\gamma$ receptor is sufficient to mediate Stat 5 activation and its repression by SOCS3. J Biol Chem 2001;276:45722-45728. 
35. Sarmay G, Angyal A, Kertesz A, et al. The multiple function of Grb2 associated binder (Gab) adaptor/scaffolding protein in immune cell signaling. Immunol Lett 2006;104:76-82.

36. Bennett $\mathrm{HL}$, Brummer T, Jeanes $A$, et al. Gab2 and Src co-operate in human mammary epithelial cells to promote growth factor independence and disruption of acinar morphogenesis. Oncogene 2008;27:2693-2704.

37. Riggins RB, Thomas $\mathrm{KS}, \mathrm{Ta} H \mathrm{HQ}$, et al. Physical and functional interactions between Cas and c-Src induce tamoxifen resistance of breast cancer cells through pathways involving epidermal growth factor receptor and signal transducer and activator of transcription $5 \mathrm{~b}$. Cancer Res 2006;66:7007-7015.

38. Fox EM, Bernaciak TM, Wen J, et al. Signal transducer and activator of transcription $5 b, c-S r c$, and epidermal growth factor receptor signaling play integral roles in estrogen-stimulated proliferation of estrogen receptor-positive breast cancer cells. Mol Endocrinol 2008:22:1781-1796.

39. Silva CM. Role of STATs as downstream signal transducers in Src family kinase-mediated tumorigenesis. Oncogene 2004;23:8017-8023.

40. Huveneers S, Danen EH. Adhesion signaling-crosstalk between integrins, Src and Rho. J Cell Sci 2009;122:1059-1069.

41. Sousa S, Cabanes D, Bougneres L, et al. Src, cortactin and Arp2/3 complex are required for E-cadherin-mediated internalization of Listeria into cells. Cell Microbiol 2007;9:2629-2643.
42. Elias BC, Suzuki T, Seth A, et al. Phosphorylation of Tyr-398 and Tyr-402 in occludin prevents its interaction with ZO-1 and destabilizes its assembly at the tight junctions. J Biol Chem 2009; 284:1559-1569.

43. Kale G, Naren AP, Sheth P, et al. Tyrosine phosphorylation of occludin attenuates its interactions with ZO-1, ZO-2, and ZO-3. Biochem Biophys Res Commun 2003;302:324-329.

44. Castano J, Solanas G, Casagolda D, et al. Specific phosphorylation of p120-catenin regulatory domain differently modulates its binding to RhoA. Mol Cell Biol 2007;27:1745-1757.

45. Piedra J, Miravet S, Castano J, et al. p120 Catenin-associated Fer and Fyn tyrosine kinases regulate $\beta$-catenin Tyr-142 phosphorylation and $\beta$-catenin- $\alpha$-catenin interaction. Mol Cell Biol 2003;23: 2287-2297.

46. Phillips N, Hayward RD, Koronakis V. Phosphorylation of the enteropathogenic $E$ coli receptor by the Src-family kinase c-Fyn triggers actin pedestal formation. Nat Cell Biol 2004;6:618-625.

47. Hayward RD, Hume PJ, Humphreys $D$, et al. Clustering transfers the translocated Escherichia coli receptor into lipid rafts to stimulate reversible activation of c-Fyn. Cell Microbiol 2009;11:433-441.

48. Dorman SE, Holland SM. Interferon- $\gamma$ and interleukin-12 pathway defects and human disease. Cytokine Growth Factor Rev 2000;11: 321-333. 